Revista de Economia Política, vol. 30, nº 2 (118), pp. 271-292, abril-junho/2010

\title{
Marshall e os críticos à economia política clássica
}

\author{
LAURA VALLADÃO DE MATTOS*
}

Marshall and the critics to the classical political economy. This paper analyzes the period of transition between the millian orthodoxy and the marshallian orthodoxy with special emphasis on the influence of the economic debates of the 1870's and 1880's in the genesis of Marshall's conceptions. It is argued that in these decades Political Economy was questioned in three different fronts: by the theoretical critics, by the adepts of the historical method, and by the humanists. It is also argued that Marshall answered these criticisms, sometimes by accepting and incorporating them, sometimes by rejecting them, and in doing so he was able to construct a new disciplinary consensus - that gave the foundations to the practice of the next generation of economists.

Keywords: classical political economy; marshall; jevons; historic method; humanist criticism.

JEL Classification: B1; B12; B13.

\section{INTRODUÇÃO}

Uma conhecida revolução no pensamento econômico separa J. S. Mill e Alfred Marshall, dois grandes pensadores da Economia Britânica. J. S. Mill foi o último grande representante da Economia Política Clássica Inglesa, já Marshall foi aquele que consolidou a Revolução Marginalista na Inglaterra. Apesar das enormes diferenças teóricas que separam as obras dos dois autores, elas desempenharam em suas respectivas épocas papéis semelhantes. Os dois pensadores encontraram a economia

\footnotetext{
* Professora do Departamento de Economia e do Programa de Estudos Pós-Graduados em Economia Política da PUC-SP. E-mail: lauramat@uol.com.br. Agradeço os comentários de Leslie Beloque, Maurício Coutinho, e José Eduardo Godoy e dos pareceristas anônimos da REP. Como bolsista de Produtividade em Pesquisa do CNPq, agradeço o apoio financeiro concedido. Submetido: Agosto 2008; Aprovado: Janeiro 2009.
} 
em crise, responderam em seus escritos às principais críticas que solapavam a confiança na disciplina e conseguiram forjar um consenso em torno de suas ideias norteando a formação e a prática de mais de uma geração de economistas.

Este artigo visa a analisar o período de crise na Economia Política Clássica e a investigar em que medida os debates ocorridos na Inglaterra nas décadas de 1870 e 1880 no campo da economia ajudaram a moldar as concepções de Marshall. ${ }^{1}$

Nesse período, várias visões alternativas sobre o que seria (e deveria ser) a Economia ganharam força e lançaram desafios teóricos, metodológicos e práticos à ortodoxia então prevalecente, ajudando a minar as suas bases. Em geral, ênfase é dada na literatura secundária a uma destas visões - a marginalista. No entanto, argumenta-se que para se entender o tipo de consenso que Marshall costurou no final do século é necessário analisar igualmente as outras correntes críticas que se apresentavam à época - a crítica historicista e a humanista. Estas também o influenciaram e forneceram elementos importantes para a formulação de suas concepções.

Com vistas a analisar esse momento de transição e o impacto das ideias então discutidas sobre o consenso que se formou a seguir, o artigo está estruturado da seguinte forma: inicialmente será analisada, em linhas gerais, a natureza da hegemonia exercida pelo pensamento de J. S. Mill na segunda metade do século XIX (segunda seção). A seguir, as críticas que as principais correntes que se opuseram à Economia Clássica lançaram contra esta escola serão analisadas bem como as respostas de Marshall a elas (terceira, quarta e quinta seções). Por fim, algumas considerações finais serão apresentadas (sexta seção).

\section{O AUGE E DECLÍNIO DA ECONOMIA POLÍTICA CLÁSSICA}

Poucos hoje em dia têm a exata noção da importância que a obra de J. S. Mill teve no pensamento econômico britânico. Todavia, a publicação dos seus Princípios de Economia Política em 1848 marcou o início de uma hegemonia e confiança na Economia Política Clássica que só viriam a ser questionadas vinte anos depois.

Segundo a descrição de Schumpeter, seguiu-se ao lançamento desta obra “(...) um estado que foi universalmente percebido como sendo de maturidade da ciência [...] um estado no qual 'o grande trabalho já tendo sido executado' a maior parte das pessoas acreditava que só restava por fazer trabalho de elaboração e aplicação no que tangia a pontos de menor importância” (Schumpeter, 1954, p. 380).

O consenso em torno da teoria milliana e a liderança de J. S. Mill tornaram-se tão grandes que levou Foxwell a afirmar que "[...] depois do aparecimento dos Princípios de J. S. Mill, os economistas ingleses, por toda uma geração, eram homens de um livro" (Foxwell, apud Keynes, 1936, p. 601). Bagehot fala em uma

\footnotetext{
${ }^{1}$ Como o escopo deste artigo se restringe aos debates ocorridos no contexto inglês, não serão tratados, por exemplo, as críticas desferidas à Economia Política pela Escola Histórica Alemã.
} 
"influência monárquica" exercida por este autor e explicita a dificuldade que existia em induzir os seus alunos a verem a disciplina com outros olhos que não os de Mill (Bageot, apud Collini et al., 1983, p. 251). Hutchison, por sua vez, aponta que J. S. Mill chegou bem perto de monopolizar o mercado de ideias econômicas na Inglaterra no período. Depois de empreender uma análise das datas de nascimento dos principais economistas do século XIX, ele conclui que, na sua época, Mill encontrava-se praticamente sozinho (Hutchison, 1972, pp. 453-454). Teria ocorrido uma espécie de entressafra de economistas

Entretanto, este alto nível de prestígio e autoridade da Economia Política teria tido um elevado custo. Segundo Foxwell, a teoria econômica: “[...] estava descansando sobre os seus louros, não mostrando qualquer sinal de crescimento ou fruto, e era vista [...] pelo público, como tendo atingido a perfeição" (Foxwell, 1887, p. 84).E, de fato, Schumpeter afirma que nas décadas que se seguiram à publicação dos Princípios a Economia Política praticamente estagnou (Schumpeter, 1954, p. 380).

No início da década de 1870 , entretanto, esta situação de confiança altera-se. ${ }^{2}$ O consenso milliano começa a quebrar-se e a Economia Política vê-se sob fogo cerrado provindo das mais variadas frentes. Passou a haver uma enorme discordância entre os economistas e fora do círculo dos economistas o conceito desta ciência despencou. Como ressalta Reisman, “[...] a intensidade da controvérsia na década de 1870 deveu-se grandemente ao alto grau de complacência e consenso observados nas duas décadas que precederam [...]" (Reisman, 1990, p. 63). Não só as políticas, mas os princípios, os valores, o método e o escopo da economia passaram a ser intensamente questionados:

“[...] na medida em que, nos anos de 1870 , ondas de críticas desabaram sobre o grande edifício [da economia de Mill], as rachaduras pareciam tão abundantes que passou a causar espanto o fato de que algum dia este tenha ficado em pé. Foi declarada temporada de caça às inconsistências dos escritos econômicos de Mill” (Collini et al., 1983, p. 252). ${ }^{3}$

Todavia, mesmo tendo perdido boa parte do seu prestígio, os Princípios Economia Política de J. S. Mill continuaram sendo utilizados em todas as mais importantes universidades até 1890, quando foram substituídos pelos Princípios de Economia de Marshall (Screpanti et al., 1995, p. 179).

\footnotetext{
${ }^{2}$ Dean (1989, p. 107), Bladen (1941, p. 18), Coats (1954, pp. 143-144) associam uma parcela do sucesso da economia política nas décadas 1850 e 1860 ao excelente desempenho da economia inglesa que se seguiu à liberação comercial, que havia sido defendida pelos economistas. Com a posterior reversão do quadro econômico no início da década de 1870, parte do seu prestígio foi perdido e críticas avolumaram-se (Coats, 1954, p. 144 E Dean, 1989, p. 116).

3. Hutchison aponta que esta perda de confiança na Economia Política Clássica foi abrupta, apesar de demorar para que outra teoria ocupasse o seu lugar. "Temos aqui um caso, quase sem paralelos na história do pensamento econômico, de um abandono repentino de um cerne teórico central que tinha prevalecido com autoridade, e por muito tempo, como uma ortodoxia estabelecida" (Hutchison, 1972, p. 466).
} 
À semelhança de toda a geração que aprendeu Economia Política na década de 1860, Marshall teve o primeiro contato com a disciplina por meio dos Princípios de J. S. Mill (Keynes, 1925, p. 10) e, já como professor, vivenciou de perto o período de crise da Economia Política Clássica. Esta formação básica e a posterior exposição às críticas a ela direcionadas foram fundamentais para gerar as suas próprias concepções. $\mathrm{O}$ seu posicionamento em relação aos principais pontos polêmicos da época ajudou este pensador a demarcar o campo e a selecionar o método para a Economia.

Além disso, a sua atitude moderada e conciliadora em relação aos críticos permitiu que angariasse os elementos necessários para forjar um novo consenso na disciplina e resgatasse o prestígio da Economia. ${ }^{4}$ Assim, com a publicação dos seus Princípios colocou um fim à ortodoxia milliana, que dominou o pensamento britânico por praticamente quatro décadas, substituindo-a por outra que durou quase o mesmo período de tempo.

Para se entender esta passagem da ortodoxia milliana para a ortodoxia marshalliana e se explicitar alguns pontos nos quais os debates das décadas de 1970 e 1980 influenciaram a natureza do novo consenso é importante fazer um mapeamento das principais correntes críticas à economia e analisar a reação de Marshall a elas.

Em grandes linhas, este mapeamento foi traçado, ainda no final do século XIX, por H. S. Foxwell em um artigo intitulado "The Economic Movement in England" (1887). ${ }^{5}$ Nele são analisadas as razões para a decadência da Economia Política Clássica (a 'velha escola de economia'), e apontadas três correntes - "[...] a crítica teórica; o método histórico e o sentimento humanista" (Foxwell, 1887, p. 87) — que teriam se fortalecido ao longo das décadas de 1870 e 1880 e que contribuíram para o surgimento do que ele denomina "nova escola de economia".

A classificação dos críticos à Economia Política nestas três grandes correntes será utilizada para organizar o restante do artigo. No entanto, é importante notar que não o trabalho não se restringirá à análise de Foxwell acerca das correntes. Inúmeros outros autores e comentadores serão utilizados na caracterização do teor das críticas teórica, histórica e humanista. Além disso, não se procurará reconstituir toda a riqueza envolvida nestes movimentos críticos — o que, sem dúvida, seria

\footnotetext{
${ }^{4}$ Apesar de crítico à Economia Clássica em muitos aspectos, Marshall foi um defensor da Economia e assumiu como objetivo reabilitar esta ciência. Como coloca Shove, "[...] Os Principios são tanto uma exposição da economia como uma apologia desta: um tipo de contra-Reforma, por assim dizer, direcionada contra as dúvidas provindas de dentro e contra das denúncias vindas de fora" (Shove, 1942, p. 310).

${ }^{5}$ Este painel tornou-se referência obrigatória para estudos sobre o período ora em análise. Foxwell teve contato próximo com alguns dos principais protagonistas das mudanças que ele analisou. Foi professor de Cambridge e muito amigo de Marshall desde a década de 1870 até 1908 quando este apoiou o jovem Pigou para substituí-lo na cadeira de Economia Política, posto também almejado por Foxwell. Segundo comentadores, Foxwell nunca teria superado esta mágoa (O’Brien 1997, p. 1871; Keynes, 1936, p. 590). Ele também conheceu Jevons em 1874 e foram amigos próximos até a morte prematura deste em 1882 (Keynes, 1936, p. 597).
} 
uma tarefa impossível de ser realizada no âmbito de um artigo. Serão selecionados prioritariamente aqueles aspectos destas correntes que, ao suscitarem um posicionamento de Marshall, ajudaram na formação da sua própria concepção.

\section{MARSHALL E A CRÍTICA TEÓRICA À ECONOMIA POLÍTICA CLÁSSICA}

A primeira frente de questionamento à Economia Política Clássica apontada por Foxwell — a crítica proveniente do campo teórico — teve, na Inglaterra, como o seu principal expoente Stanley Jevons.

Jevons opôs-se frontalmente à Escola de Ricardo e J. S. Mill (que ele considerava ser um seguidor de Ricardo) e contra a "influência nociva" que a sua autoridade teria exercido na economia, impedindo que algumas contribuições "corretas" de autores como Malthus e Senior fossem consideradas ou incorporadas à ciência (Jevons, 1996, p. 40). No seu livro A Teoria da Economia Política, cuja primeira edição saiu em 1871, Jevons defendeu que, para se chegar a uma teoria verdadeira, seria necessário "[...] deixar de lado, de uma vez por todas, as suposições confusas e absurdas da Escola ricardiana” Jevons, 1996, p. 36), e começar novamente.

Ele propôs uma redefinição da Economia que incluía a divisão do amplo campo que a Economia Política abarcava em vários ramos ou ciências. Segundo ele, "[...] se faz necessário subdividir uma esfera demasiado extensa de conhecimento [...] só mediante o reconhecimento de um ramo da sociologia econômica, possivelmente com 2 ou 3 outros ramos da ciência estatística, jurídica ou social, podemos salvar a nossa ciência desse estado desordenado." (Jevons, 1996, p. 37).

Nos demais ramos ou ciências Jevons aceitava a pertinência de outros métodos, mas julgava que a Teoria Econômica - o estudo dos princípios mais gerais da ciência da Economia - deveria ser investigada pelo método dedutivo (Collini et al., 1983, p. 319) e ter no seu centro "[...] a mecânica do interesse e da utilidade [...]" (Jevons, 1996, p. 22). Isto significava, entre outras coisas, adotar uma teoria subjetiva do valor na qual "[...] o valor depende inteiramente da utilidade [...]" (ibid., 47) que era totalmente diferente da visão então prevalecente sobre valor.

Além disso, Jevons sustentou com ardor a tese de que a matemática (especialmente o cálculo diferencial) seria a linguagem adequada à Economia e, de fato, seu livro é povoado por inúmeras equações e gráficos. Uma vez que esta posição representava uma quebra importante com a ortodoxia vigente, Jevons procura justificá-la:

"Parece-me que nossa ciência deve ser matemática, simplesmente porque lida com quantidades. Onde quer que os objetos tratados sejam passíveis de ser maior ou menor, aí as leis e relações devem ser matemáticas por natureza. As leis usuais da oferta e da procura [...] são matemáticas. Os economistas não podem alterar a sua natureza recusando-se a 
assim denominá-las; seria como [...] tentar alterar a luz vermelha ao denominá-la azul”(Jevons, 1996, p. 48). ${ }^{6}$

Em grandes linhas, podemos dizer que as ideias de Marshall eram próximas às de Jevons. $\mathrm{E}$, se confiarmos nos seus próprios relatos e nos de Keynes, Marshall pode até ser visto como um dos formuladores de algumas das principais críticas do movimento de crítica teórica.

Marshall sempre afirmou que chegou às suas ideias de forma independente. Nos Prefácios aos Princípios ele reconhece como precursores apenas Cournot e von Thünen e em carta direcionada ao Prof. Colson, afirma a precedência de seu trabalho em relação ao de Jevons: "Antes de 1871 quando a importante Teoria da Economia Política de Jevons apareceu, eu já havia desenvolvido todo o esqueleto de meu sistema atual em termos matemáticos, apesar de não em inglês" (Marshall [1907], 1933, p. 221).

Keynes também testemunha que em 1871 Marshall já havia avançado consideravelmente em sua teoria e sugere que a publicação do livro de Jevons deve ter-lhe causado uma grande decepção, pois tirou "[...] o ar de novidade das novas ideias que Marshall estava vagarosamente construindo, sem dar a elas - no entender de Marshall - um tratamento adequado" (Keynes, 1925, pp. 21-22). Na avaliação de Keynes, "Jevons viu a chaleira ferver e anunciou isso com a voz deliciada de criança. Marshall também havia visto a chaleira ferver, e sentou silenciosamente para construir um motor a vapor" (Keynes, 1925 , p. 23). ${ }^{7}$

De qualquer forma, apesar das grandes semelhanças principalmente no que tange ao conceito de utilidade marginal decrescente e à utilização do cálculo diferencial na economia, a receptividade inicial de Marshall às ideias de Jevons não foi favorável. Ele fez questão de distanciar-se das posições deste autor e, apesar de os dois manterem relações profissionais cordiais, na correspondência com amigos Marshall mostrava-se bastante crítico. Segundo O’Brien, “[...] Marshall denegria Jevons por razões técnicas, era condescendente com a sua matemática e era crítico de Jevons enquanto teórico"(O’Brien, 1997, p. 1870). ${ }^{8}$

\footnotetext{
${ }^{6}$ Ver também Jevons (1996:24). Foxwell aponta a adoção da análise matemática como sendo, ao lado da rejeição à teoria do fundo de salários, a contribuição mais relevante dessa corrente de crítica teórica (Foxwell, 1887, p. 88). Jevons destacou-se também no segundo aspecto. Como aponta Hutchison (1972, pp. 460-467), ele rejeitou frontalmente a teoria do fundo de salários e a ideia de salário natural — dois pilares da tradição Ricardo-Mill.

${ }^{7}$ Há uma controvérsia na literatura sobre se Marshall de fato desenvolveu de forma independente a sua teoria ou se foi influenciado por Jevons - principalmente no que concerne ao princípio da utilidade marginal decrescente. Schumpeter (1941, p. 239) e Shove (1942, p. 295), acreditam que Marshall chegou às suas ideias de forma independente - por meio da tentativa de "traduzir" para a matemática as contribuições de J. S. Mill e Ricardo. Schabas (1989), ao contrário, acredita Jevons pode ter influenciado Marshall mais do que ele estaria pronto a admitir (Schabas, 1989, p. 67).

${ }^{8}$ Posteriormente, Marshall mudou a sua avaliação sobre Jevons e passou a situá-lo entre os grandes economistas (Schabas, 1989, p. 66). Robbins (1982, p. 310) aponta, inclusive, que Marshall veio a atribuir ao Jevons o status de Clássico que negou ao J. S. Mill.
} 
Um dos pontos que mais incomodava Marshall era a ferocidade de suas críticas em relação à escola ricardiana-milliana (O'Brien, 1997, p. 1870). ${ }^{9}$ Em seus Princípios, Marshall deliberadamente utilizou um tom bastante diferente do discurso radical de Jevons, frisando sempre o aspecto de continuidade em relação à tradição anterior. Segundo ele, "[...] as novas doutrinas têm completado as antigas, as têm estendido, desenvolvido [...] porém muito raramente as têm subvertido"(Marshall, [1920], 1982, p. v). Sobre a atitude de ruptura de Jevons, afirma: “[...] ele induziu várias pessoas a acreditarem que ele estava corrigindo grandes erros, quanto estava somente adicionando explicações muito importantes" (Marshall [1920], 1982, p. 85).

Apesar de ter fundado a curva de demanda na lei da utilidade marginal decrescente, Marshall criticou também a postura de Jevons em relação à teoria do valor. Para ele, ao enfatizar o lado da utilidade, este acabou por deixar de fora o papel da produção na determinação do valor das mercadorias. Na sua avaliação, a afirmação de Jevons de que o valor dependeria inteiramente da utilidade, "[...] não é menos unilaterial e fragmentada, e é bem mais enganosa" (Marshall [1920], 1982, p. 673) do que aquela de Ricardo sobre o valor ser determinado pelo custo de produção. Marshall introduz, então, a sua famosa metáfora da "tesoura" na qual utilidade e custo de produção constituiriam as suas lâminas e conjuntamente determinariam o valor (Marshall [1920], 1982 , p. 675).

De fato, ao reintroduzir o "lado" da oferta, Marshall adota uma perspectiva mais próxima daquela dos Clássicos do que Jevons. No entanto, a continuidade que ele procura traçar em relação à tradição anterior é, em grande medida, enganosa. Ele adota, também na esfera da produção, uma teoria subjetiva do valor que está calcada nos "sacrifícios" relacionados a esta - basicamente aqueles referentes ao trabalho e à "espera” (Marshall [1920], 1982, p. 116). Como coloca Shove, “[c] om a emergência do conceito psicológico de "custo real" entramos não simplesmente num mundo diferente daquele de Ricardo, mas em um Universo diferente" (Shove, 1942, p. 306). Apesar do discurso de continuidade, a teoria de Marshall encontra-se totalmente fora do âmbito da teoria do valor trabalho de Ricardo. ${ }^{10}$

Sob influência das outras correntes críticas, Marshall também apresenta restrições em relação à ideia de Jevons de reduzir drasticamente o escopo da Economia

\footnotetext{
${ }^{9}$ Marshall afirma: “[...] a genialidade que permitiu a Ricardo [...] costurar de forma segura o seu caminho através das mais escorregadias passagens de raciocínio matemático [...] tinha tornado-o um dos meus heróis; e a minha lealdade juvenil a ele ferveu quando eu li a Teoria de Jevons."(Marshall, apud Schabas, 1989, p. 65). Reisman (1990, pp. 106-113) aponta várias semelhanças entre as teorias de Marshall e de Ricardo - J. S. Mill que poderiam também justificar esta reverência para com os predecessores.

${ }^{10}$ Argyrous vê um esforço consciente por parte de Marshall em traçar uma linha de continuidade com os Clássicos e aponta três possíveis motivos para essa estratégia:1) a avaliação de que a ideia de continuidade seria útil para o estabelecimento do marginalismo como paradigma; 2) a ideia de que a chance de estabelecer um Tripos independente de economia em Cambrigde seria maior caso se criasse uma imagem de continuidade na economia; 3 ) a tentativa de elevar o seu prestígio ao sugerir que as contribuições de Jevons e Walras não teriam sido tão importantes uma vez que os principais elementos da “nova economia” já se encontrariam na tradição anterior (Argyrou, 1990, p. 53).
} 
Política - centrando a análise teórica na dinâmica do interesse e da utilidade - e de investigá-la apenas por meio método dedutivo. Como apontam Collini et al., Marshall "[...] repudiou a identificação da "economia em si" unicamente com a "teoria", mantendo que "um estudo minucioso dos fatos é igualmente essencial, e que a combinação dos dois lados [fatos e teoria] é economia em si". Como resultado ele não podia aprovar a fragmentação que Jevons havia defendido [...]" (Collini et al., 1983, p. 319).

Marshall mostrou-se também mais reticente que Jevons em relação à utilização da matemática na economia. Apesar de matemático por formação e de utilizar intensamente este instrumento para chegar às suas formulações, ele optou deliberadamente por não introduzir a linguagem matemática no corpo principal dos seus Princípios, relegando-a a notas de rodapés e apêndices. ${ }^{11}$ Esta atitude explica-se, em grande medida, pelo seu desejo de atingir um público mais amplo (Schabas, 1989, p. 69; Schumpeter, 1941, p. 240). Além disso, Schumpeter aponta que Marshall, “[...] tinha medo, e com razão, de dar o exemplo que poderia induzir pessoas com treinamento matemático a achar que a matemática é tudo que um economista precisa." (Schumpeter, 1941, p. 240).

Essa reação moderada em relação às críticas teóricas lançadas contra a Economia Política Clássica, escamoteou rupturas importantes, mas foi fundamental para conseguir angariar a simpatia daqueles que foram formados na tradição de Ricardo e J. S. Mill e que não tinham treinamento matemático suficiente para acompanhar seus diagramas e derivações.

\section{A CRÍTICA PROVENIENTE DO “CAMPO HISTÓRICO” E MARSHALL}

Um segundo movimento crítico à Economia Política que será abordado é o dos adeptos do método histórico. Foxwell agrupa neste movimento autores, como Comte, Spencer e Darwin (que introduziram analogias biológicas), Austin, Main, Cliffe Leslie, John Ingram (historicistas), e, por último, autores influenciados pela metafísica alemã, como Proudhon e Marx (Foxwell, 1887, p. 89). Pode-se questionar a classificação de autores tão diversos sob uma mesma denominação, no entanto, para os propósitos deste trabalho, a agregação feita por Foxwell se justifica. Isto porque os elementos que Marshall introduziu ao seu pensamento por conta destas influências foram basicamente, a noção de dinâmica, de história e de evolução das instituições sociais - noções estas presentes nas três vertentes que Foxwell associa ao método histórico.

Como aponta Dean (1989) a teoria darwiniana da evolução teve muita influên-

\footnotetext{
${ }^{11}$ Apesar desta atitude para com a matemática, Schabas e Schumpeter frisam a importância que ela teve para o desenvolvimento da teoria do autor. Para Schabas " [...] o catalizador principal para as descobertas de Marshall foi a matemática em si” (Schabas, 1989, p. 68). Schumpeter (1941, p. 240), por sua vez, diz que Marshall “[...] nunca deu crédito integral à sua fiel aliada. Ele escondeu o instrumento que executou o trabalho.” (Schumpeter, 1941, p. 240).
} 
cia no pensamento social das décadas finais do século XIX e nela "[...] a história natural e a história humana foram vistas como um processo contínuo único de desenvolvimento" (Dean, 1989, p. 124). Mas como apontam Hodgson (1993, p. 407) e Reisman (1990, p. 65) e a própria Dean (1989, p. 125), foi através da teoria social de Spencer que a biologia influenciou mais diretamente a Economia. A insistência destes teóricos nos conceitos de organismo, dinâmica perpétua, evolução e interdependência geral colaborou para a crise que vivia esta ciência (Resiman, 1990, p. 65). Dada a nova visão relacionada à evolução, o ambiente intelectual passou a ser mais propício para formulações que tivessem flexibilidade e menos favorável à utilização de princípios abstratos e universais, como os associados à Economia Política na época.

Entretanto, dentre as vertentes históricas apontadas por Foxwell, a que foi mais influente e causou mais "rachas" entre os economistas britânicos das décadas de 1870 e 1980 foi, sem dúvida, a Escola Histórica — que tinha como principais representantes na Inglaterra John Ingram e Cliffe Leslie - e, por esta razão, será analisada de forma mais detida. ${ }^{12}$

No que concerne à Economia Política, segundo Coats, os componentes da Escola Histórica em linhas gerais "[...] protestavam contra a estreiteza de seu escopo; [...] reclamavam da excessiva confiança no método dedutivo-abstrato de raciocínio, e da aplicação dogmática das conclusões na esfera das políticas [policy]"(Coats, 1954, p. 144).

No que se refere ao escopo, eles questionavam a possibilidade de se realizar um estudo autônomo da Economia Política. J. S. Mill havia definido esta ciência como tendo no seu centro a motivação busca da riqueza e isso permitiu que fosse tratada como um ramo semi-autônomo da Sociologia e fosse investigada pelo método dedutivo (Mill [1836], 1967; Mill [1843], 1987; Mattos, 1999). Mas os historicistas recusaram fortemente este recorte. Foi, inclusive, ao criticar a posição milliana que John Ingram inventou o termo "homem econômico" - tão largamente utilizado desde então. Segundo ele, J. S. Mill "[...] não lidou com homens reais e sim com homens imaginários — "homens econômicos" [...] concebidos apenas como animais acumuladores de dinheiro [money-making animals]" (Ingram, apud Persky, 1995, p. 222).

Assim, a rejeição ao "homem econômico" envolvia também uma rejeição à ideia de que seria possível estudar a Economia Política de forma autônoma e por meio do método dedutivo, uma vez que estes elementos estavam todos intimamente relacionados nas concepções de J. S. Mill. Numa linha comtiana, os historicistas acreditavam que os fenômenos econômicos só poderiam ser entendidos quando analisados conjuntamente com os demais fenômenos sociais. E, de fato, na interpretação de Collini et al., a proposta de Cliffe Leslie para a Economia parecia “[...]

\footnotetext{
${ }^{12}$ Não trataremos da terceira linha adepta ao método histórico (Proudhon, Marx e outros autores influenciados pela metafísica alemã), porque, apesar de ter tido contato com ela, esta influenciou Marshall em pontos semelhantes e em medida menor dos que as demais aqui discutidas.
} 
equivaler a uma sociologia histórica [...] na qual os arranjos econômicos eram relacionados a mudanças no gosto, nos valores religiosos e morais, nos arranjos políticos e legais e assim por diante [...]" (Collini et al., 1983, pp. 263-264).

Os adeptos da Escola Histórica inglesa desejavam substituir a dedução a partir de princípios universalmente válidos, pela prática de "[...] comparar sociedades em diferentes estágios de desenvolvimento, para formular 'leis da evolução social'” (Coats, 1954, p. 149), o que implicava uma análise histórica e dinâmica. Adicionalmente, acreditavam que as leis e os movimentos da sociedade deveriam ser obtidos basicamente por meio da observação e indução (Bladen, 1941, P. 21).

Por fim, vale ressaltar que, apesar de boa parte da polêmica dos historicistas com a Economia Política Clássica girar em torno de questões metodológicas, a discussão não era puramente abstrata ou "acadêmica". Pelo contrário, no cerne do embate estava um questionamento dos princípios da Economia Política que embasavam a defesa (muitas vezes dogmática) do laissez-faire e de outras políticas econômicas e sociais. ${ }^{13}$ Como apontam Collini et al., "[s]obretudo o seu papel de comando nas discussões dos assuntos públicos foi o que fez da economia um prêmio pelo qual tão claramente valia a pena lutar [...]" (Collini et al., 1983, p. 275).

Marshall foi bastante influenciado por estas correntes adeptas do método histórico, incorporou muitas das críticas lançadas por elas contra a Economia Política e mobilizou-se para rebater outras que julgava inadequadas, ou demasiadamente radicais.

Claramente aceitou a crítica desta corrente à postura adotada pelos economistas políticos de aplicar de forma dogmática as suas "leis" sem considerar as diferenças culturais, sociais e institucionais existentes entre os diferentes países ou mesmo entre diferentes regiões de um país. Para Marshall, o objeto da economia não seria estático e sim dinâmico e histórico. Segundo ele, os economistas clássicos, falharam ao não levarem em conta o fato de a natureza humana ser mutável (Marshall, 1885 , p. 153). Esta postura decorria, no seu entender, de terem adotado como modelo uma ciência - a Física - cujo objeto de estudo é imutável e constante não importando o país ou a época (Marshall, 1885, p. 154). Por conta disso, teriam tratado da mesma forma o seu próprio objeto:

"Eles encaravam o homem como [...] uma quantidade constante, e se preocuparam pouco com o estudo das suas variações. As pessoas que eles conheciam eram basicamente pessoas da City, e [...] [a] mesma tendência de mente que levou os nossos advogados a imporem a lei civil inglesa aos hindus, levou nossos economistas a trabalharem suas teorias com a suposição tácita de que o mundo é constituído por homens da City” (Marshall, 1885, p. 155).

\footnotetext{
${ }^{13}$ Os historicistas se voltaram para a análise histórica para tentar, entre outras coisas, evidenciar que o “[...] laissez-faire não constituía uma dedução apolítica a partir da análise de forças econômicas naturais"(Collini et al., 1983, pp. 257-258). Seria uma política e como tal não era adequada à sua época. Sobre a motivação "prática” dos historicistas ver também Dean (1989, p. 121) e Coats (1954, p. 144).
} 
Segundo Marshall, a Biologia forneceria analogias melhores para a Economia, pois explicitaria o crescimento orgânico das coisas. Mirando-se nesta ciência poderse-ia perceber que "[...] se o objeto da ciência passa por diferentes estágios de desenvolvimento, as leis que se aplicam a um estágio dificilmente aplicar-se-ão a outro sem modificações; [e que] as leis da ciência devem ter um desenvolvimento correspondente àquele das coisas com que lida" (Marshall, 1885, p. 154). ${ }^{14}$

Assim, Marshall posicionou-se contra atribuir um caráter universalista aos princípios da Economia Política. Para ele estava claro que a doutrina econômica não seria "[...] um corpo de verdades concretas, e sim um mecanismo de descoberta de verdades concretas [...]" (Marshall, 1885, p. 159), e que estas verdades poderiam variar (e provavelmente variariam) conforme as circunstâncias.

Esta postura metodológica é apontada por Keynes como a principal razão pela qual Marshall demorou 20 anos para publicar as suas ideias. Segundo Keynes, ele tinha uma grande preocupação em não apresentá-las como princípios abstratos. O interesse estaria "[...] em aplicá-los à interpretação da vida econômica cotidiana" (Keynes, 1925, p. 33), o que requeria um conhecimento profundo dos fatos econômicos. Como o mundo e o homem estavam em processo de rápida transformação, Marshall temia que a apresentação dos princípios e diagramas desvinculados de suas aplicações pudesse acarretar utilizações equivocadas e universalistas (ibidem).

Essa visão do empreendimento científico fez também com que aderisse à crítica lançada pelos historicistas contra o status de "princípios" atribuído pelos economistas clássicos a algumas políticas econômicas, por ex. ao laissez-faire. Para Marshall, estas políticas poderiam servir para algumas épocas e localidade e não para outras. E considerava que a Escola Histórica havia feito avançar a investigação científica justamente ao pregar o "[...] abandono de proposições gerais e dogmas, em favor de um processo de análise cuidadosamente trabalhado e disponível (held ready) para a aplicação às circunstâncias especiais de problemas particulares relacionados a diferentes países e épocas [...]" (Marshall, apud Coats, 1954, p. 151). ${ }^{15}$

Marshall aceitou igualmente as críticas historicistas à adoção do "homem econômico", apesar de rejeitar a solução por eles apresentada. Ele discorda explicitamente de J. S. Mill que, como mencionado, havia definido a ciência da Economia Política como uma ciência dedutiva e semiautônoma com base nesta abstração. No

\footnotetext{
${ }^{14}$ Todavia, apesar das afirmações de Marshall sobre a superioridade da metáfora biológica, Hodgson, (1993, pp. 406-408) argumenta que a análise biológica não chegou a ser integrada de forma orgânica nos Princípios. Para ele, "[a] facilidade com que a biologia foi posteriormente purgada do sistema marshalliano, para ser substituída por uma metáfora fortalecida proveniente da mecânica, sugere o grau altamente limitado no qual ideias distintamente biológicas foram originalmente implantadas por Marshall em seus Princípios” (Hodgson, 1993, p. 413).

${ }^{15}$ Ele defendeu, no entanto, os seus predecessores ao afirmar que a má fama da Economia Política deveu-se muito aos divulgadores que tiraram as conclusões da economia política de contexto e a elevaram a um dogma. Vemos aqui mais uma instância de como, mesmo quando Marshall se coloca em campo oposto ao dos Clássicos, ele tenta defendê-los.
} 
entender de Marshall, a Economia "[...] é um estudo da Humanidade nas atividades cotidianas da vida” (Marshall [1920], 1982, p. 1), e “[...] examina aquelas partes da ação individual e social mais estritamente ligadas à obtenção e à utilização de quesitos materiais do bem estar"(ibidem). E frisa, contrariando a visão de J. S. Mill, que esta ciência "[...] lida com o homem tal como ele é; não com um homem abstrato ou "econômico"; mas com o homem de carne e osso [...]" (Marshall [1920], 1982, p. 22), que tem diversas motivações, e nem todas auto-interessadas (ibidem). ${ }^{16}$

Não adere, entretanto, à posição dos adeptos da Escola Histórica que defendiam o fim da autonomia da Economia Política e sua virtual "dissolução" na grande Ciência Social. Marshall até demonstra alguma simpatia em relação a essa ideia, no entanto, argumenta que uma vez que a Ciência Social unificada ainda não existia, e não dava sinais de que viria a existir tão cedo, não seria sábio desprezar o conhecimento (mesmo que fragmentado) que a Economia tinha a oferecer (Marshall,1885, p. 164). Defende, portanto, a utilidade da investigação autônoma deste campo dos fenômenos sociais.

No entanto, ao rejeitar a abstração "homem econômico", Marshall minou o pilar sobre o qual J. S. Mill apoiou o seu pleito pela autonomia, mesmo que relativa, da ciência da Economia Política. Marshall precisou defender, portanto, a pertinência de manter o estudo autônomo desta ciência com base em outro argumento. E o argumento utilizado foi o de que no campo dos fenômenos econômicos seria possível, mesmo que de forma imperfeita, medir a força das motivações humanas. E, para tanto, não seria necessário abstrair nenhuma delas - estas poderiam ser de natureza egoísta ou altruísta, contanto que tivessem uma medida monetária poderiam ser abordada pela economia (Marshall [1920], 1982, pp. 20-23; Shove, 1942, p. 310).

Assim, apesar de mostrar alguma simpatia em relação ao projeto de se construir uma grande ciência social, concretamente Marshall reafirma a importância da ciência econômica vis-à-vis as pretensões de dissolvê-la na grande Sociologia. E o fato é que Marshall foi o responsável por estabelecer o Tripos de Economia em Cambridge, tornando este curso independente daquele de filosofia moral, ao qual anteriormente era subordinado. ${ }^{17}$

$\mathrm{Na}$ questão sobre qual seria o método de investigação adequado à ciência econômica, a sua posição também é intermediária. Apesar de mostrar mais aber-

\footnotetext{
${ }^{16}$ Para Collini et al. esta definição de economia “[...] marcou uma quebra decisiva com o postulado do "homem econômico" e, portanto, com todas as conotações restritivas, abstratas, egoístas, e demasiadamente materialista deste postulado" (Collini et al., 1983, p. 314).

${ }^{17}$ Quando assumiu a sua cadeira de Economia Política nesta universidade esta disciplina fazia parte do Tripos de Ciências Morais. Em 1870 esta era constituído por Filosofia Moral, Psicologia e Economia Política (Groenewegen, 1988, pp. 74-75). Marshall lutou para tornar a economia uma disciplina autônoma uma vez que, para ele, esta ciência estaria perdendo a contribuição de pessoas com mentes científicas, mas sem o gosto pela totalidade das Ciências Morais (Marshall, 1885, p. 171). Esta foi uma briga que Marshall abraçou com ardor, e seu esforço foi bem-sucedido — em 1903, Marshall finalmente viu o Tripos de Economia ser criado em Cambridge (Groenewegen, 1988, p. 87).
} 
tura do que alguns dos seus antecessores no que concerne ao papel da indução na ciência econômica, Marshall não se deixou levar pela ideia de torná-la uma ciência indutiva e reduzi-la, na prática, a uma série de estudos de casos. Para ele, apesar de a visão histórica ser importante e de ser necessária uma análise cuidadosa dos fatos relacionados a cada circunstância específica, a teoria seria fundamental.

"Por mais ávido por fatos que o economista tenha que ser, ele não pode contentar-se com meros fatos [...] Ele tem que manter-se firme no projeto mais árduo de interrogar os fatos de forma a aprender o modo de ação das causas individualmente e conjuntamente, aplicando esse conhecimento para construir um corpo [organon] de teoria econômica, e depois fazer uso da ajuda fornecida por esse corpo [organon] para lidar com o lado econômico dos fenômenos sociais. Ele irá, assim, trabalhar à luz dos fatos, mas a luz não será dirigida diretamente, ela será refletida e contrastada pela ciência” (Marshall, 1885, p. 171).

Como apontam Collini et al., Marshall genuinamente valorizava a história, no entanto, a função que ele atribui a esta é diferente daquela conferida pelos adeptos da Escola Histórica. Para Marshall sem o conhecimento causal (que é fornecido pela teoria) os fatos derivados da história ou da observação não podem servir de guia para conduta futura (Collini et al., 1983, p. 323). Segundo ele, “[...] os fatos sozinhos são silenciosos. A observação não descobre nada diretamente sobre a ação das causas, mas somente sobre sequências no tempo"(Marshall, 1885, p. 166). Somente a explicação teórica da evolução histórica poderia fornecer os elementos para a predição (Collini et al., 1983, p. 327). Assim a indução e a dedução seriam, para Marshall métodos necessários e complementares:

“[A] resposta de Marshall [ao desafio lançado pela Escola Histórica] foi a por meio da combinação de métodos — não somente a história permeada por teoria, mas teoria (como nos Princípios) nutrida, modificada e ilustrada por fatos históricos e contemporâneos" (Shove, 1942, pp. 308-309). ${ }^{18}$

Pode-se afirmar que a posição que Marshall adota em relação ao escopo e ao método da Economia, se bem que bastante distinta daquela sustentada pelos adeptos do método histórico, foi moldada pelo esforço de se posicionar em relação às suas principais críticas à Economia Política. Ao aceitar alguns e descartar outros pleitos desta corrente, Marshall acabou por definir o que considerava ser o campo

\footnotetext{
${ }^{18}$ Sobre esta mistura de métodos, Schumpeter afirma: “[...]atrás, além e ao redor daquele cerne [aparato analítico] existe uma sociologia econômica do capitalismo Inglês do século XIX que se apoiava numa base histórica de extensão e solidez notáveis. Marshall era, de fato, um historiador econômico de primeiro nível (...) e seu domínio de fatos históricos e seu hábito analítico de mente não trabalhavam em compartimentos separados, mas formavam uma união tão próxima que o fato vivo invade o teorema e o teorema invade as observações puramente históricas (...)” (Schumpeter, 1941, p. 238).
} 
e a forma de investigação da Economia. Como afirma Shove, o contato de Marshall com a Escola Histórica, e sua ansiedade em dar conta das críticas que ele julgou pertinentes, explica em alguma medida o formato e a abordagem adotada nos Princípios. Segundo ele, "[s]e alguma escola de pensamento, excetuando a tradição de Ricardo, deixou sua marca nos Princípios foi a Escola Histórica, e não a escola de utilidade marginal, que o fez" (Shove, 1942, p. 309).

De qualquer forma, apesar de não aceitar muitas das proposições desta corrente, o respeito que Marshall mostrou pela História e o fato de valorizar algumas de suas contribuições, ajudaram a apaziguar a disputa metodológica que consumia a disciplina há quase duas décadas. ${ }^{19}$

\section{O SENTIMENTO HUMANISTA E MARSHALL}

A última frente de crítica à Economia Política citada por Foxwell - e que também deixou sua marca nas concepções de Marshall — foi a derivada do sentimento humanista. Esse tipo de ataque contra a Economia Política, que havia tido alguma repercussão na década de 1830 e nunca deixou de encontrar eco na sociedade britânica, voltou a ser influente com a queda de prestígio da Escola de Ricardo-Mill. No final do século XIX, a imagem que a opinião pública em geral tinha da Economia Política (principalmente da ricardiana) não era das mais favoráveis. ${ }^{20}$ O próprio Foxwell faz uma caracterização pouco simpática da "velha escola":

"No seu espírito, ela era fortemente materialista, sacrificando o bem estar nacional pela a acumulação de riqueza individual [...] Pior de tudo, ela era distintamente amoral (um defeito muito mais sério do que a imoralidade, que provoca uma reação), na medida em que ela alegava que a ação econômica era sujeita a um sistema mecânico de leis, de um caráter certo [positive], independente e superior a quaisquer leis do mundo moral [...]" (Foxwell, 1887, p. 85).

As ideias dos românticos ingleses como Thomas Carlyle e John Ruskin cristalizavam muitos dos sentimentos sociais anti-Economia Política. Foi inclusive Carlyle que inventou o apelido de ciência lúgubre ("dismal science") para esta ciência. ${ }^{21}$

\footnotetext{
${ }^{19}$ Reisman (1990, pp. 72-74), mostra como o tom conciliador que Marshall adotou já em 1885 na palestra proferida quando assumiu a cadeira de Economia Política em Cambridge, deixou os adeptos dos movimentos historicistas relativamente satisfeitos.

${ }^{20}$ Como indica Shove:“[...] de forma mais geral, talvez, do que qualquer época antes [...], os "economistas políticos" eram agora "vistos como seres sem coração (cold-bloded) desprovidos dos sentimentos comuns de humanidade" que negligenciavam os imponderáveis em favor de fatos duros e enfatizavam a busca sórdida de riqueza material até a exclusão das emoções mais ternas e as aspirações mais elevadas do homem [...]" (Shove, 1942, p. 309).

${ }^{21}$ Persky (1990) aponta que a Economia deveria ficar feliz com este apelido, pois poderia ter sido bem
} 
Eles consideravam os valores e princípios dos economistas políticos degradantes para humanidade em termos econômicos, políticos, artísticos e morais (Persky, 1990, p. 169). ${ }^{22}$

Em linhas gerais estes românticos defendiam uma sociedade paternalista, na qual os ricos cuidariam dos pobres - garantindo que tivessem empregos, fossem alimentados, vestidos e educados em termos morais - e os pobres, como contrapartida, teriam o dever de serem homens respeitosos e religiosos, além de trabalhadores responsáveis. Os vínculos sociais deveriam, nesta concepção, estar fundados em uma rede de direitos e obrigações. Todavia, a ordem de mercado teria, segundo Carlyle, substituído "[...] o sistema de direitos e deveres pelo elo do dinheiro [cash nexus] [...]” (Grampp, 1972, p. 368), o que parecia a estes pensadores detestável.

Pelo menos desde Adam Smith, os economistas argumentavam que este sistema de mercado poderia funcionar bem e que as trocas mercantis seriam mutuamente vantajosas para os indivíduos envolvidos. No entanto, a própria forma de se colocar a questão parecia ultrajante a Carlyle, Ruskin e demais românticos. Para eles, “[...] os homens deveriam juntar-se para cumprir suas obrigações mútuas e não para verem o que podem tirar uns dos outros [...] a ofensa está em cada pessoa ver a outra como um meio de conseguir algo [...]" (Grampp, 1972, p. 368).23

A Economia Política era considerada por estes críticos a grande promotora de valores da sociedade industrial como a ganância, competição, e uma defensora da acumulação a qualquer preço - a própria caracterização do homem como um homem econômico parecia evidenciar isto. Não é surpreendente, portanto, a animosidade deles em relação a esta ciência.

Todavia, apesar de ser bastante influente, esta não foi a única vertente de crítica humanista, Foxwell cita igualmente os defensores dos Atos Fabris e os adeptos do Movimento Socialista Cristão e outros movimentos sociais que acusavam a Economia Política de ter pouca preocupação com o destino dos trabalhadores, de assumir posições desumanas e de não se importar com os pobres. Estes movimentos criticavam com especial ênfase a Teoria dos Fundos de Salários adotada pelos economistas, cuja principal implicação prática seria a virtual inutilidade de as classes trabalhadoras lutarem por melhores condições.

pior. Ruskin a denominou "bastard science", Southey chamou-a de "pseudo science", Arnold falava da "one-eyed race" of economists, e o próprio Carlyle referiu-se à economia política (e ao utilitarismo) como sendo uma "pig-philosophy" (Persky, 1990, p. 171).

${ }^{22}$ Como coloca Winch:“[...] os poetas estavam reagindo [...] contra as características perturbadoras da cena contemporânea: materialismo e uma crescente crença no poder de máquinas e no pensamento mecanicista; o "individualismo agressivo do período"; o declínio da benevolência e paternalismo associado à "velha ordem"; a dissolução da "humanidade" e das "afetividades sociais" do homem.[...] A Economia Política era vista como a epítome intelectual dessas mudanças sociais" (Winch, 1985, p. 19).

${ }^{23}$ Além desta crítica moral, Carlyle temia as consequências de se adotar o laissez-faire, ou de confiar a ordem social ao "cash nexus". Ele acreditava que sem uma relação paternalista permanente, “[...] os empregadores eram encorajados a explorarem seus trabalhadores na sua ignorância e pobreza. Ao mesmo tempo, os trabalhadores naturalmente tentavam evadir-se nos seus esforços” (Persky, 1990, p. 170) - o que teria efeitos morais e materiais perversos. 
Marshall mostrou-se bastante sensível às reflexões apresentadas por essa corrente crítica à Economia Política. O tom moral e piedoso de boa parte das objeções delineadas coadunava perfeitamente com os seus valores e, também neste caso, ele mobilizou-se para fornecer uma resposta aos vários aspectos destas que julgou serem pertinentes.

A rejeição ao homem econômico por parte deste autor envolvia, como observado, a visão de que o homem de "carne e osso", com todas as suas motivações - e não o homem considerado apenas como um ser aquisitivo - deveria ser o objeto de estudo da economia. Do ponto de vista moral isto significava que as motivações de natureza mais nobres e elevadas dos homens, e não apenas as egoístas, poderiam ser tratadas pela ciência. ${ }^{24}$

Ele se esforça por esclarecer que a Economia enfatizava a busca da riqueza não por considerar a ganância ou a mesquinhez valores louváveis, ou por defender a acumulação de capital como o mais importante fim a ser buscado pelos homens, mas pelo fato de o dinheiro ser uma medida (mesmo que defeituosa) da força das motivações (Marshall, 1885, p. 159; Marshall, [1920], 1982, pp. 12-23)::25

"[...] Ainda que seja verdadeiro que o "dinheiro" [...] ou o "comando sobre riqueza material" sejam o centro ao redor do qual a ciência econômica se agrupa; isto ocorre não pelo fato de o dinheiro ou a riqueza material serem vistos como o objetivo principal do esforço humano, nem mesmo como provendo o principal assunto do estudo dos economistas, mas porque, neste nosso mundo, é o único meio conveniente de medir as motivações humanas em uma larga escala" (Marshall, [1920], 1982, p. 18).

A própria preocupação de Marshall em eleger a deliberação ao invés da competição como a principal marca da economia da sua época (Marshall [1920], 1982, pp. 4-8), pode ser vista como uma tentativa de diminuir a associação existente nas mentes das pessoas entre o agir econômico e o egoísmo. Como apontam Collini et al., "[i]sso abria espaço para cooperação deliberada e para não-egoísmo deliberado [deliberate unselfishness] [...] no qual a riqueza material era sacrificada com vistas a melhoramentos na 'qualidade da vida'” (Collini et al., 1983, pp. 314-315). E,

\footnotetext{
${ }^{24}$ Como explicitam Collini et al., "Marshall resistia à ideia de que a disciplina estava confinada a lidar com indivíduos autointeressados, cujas ações, seja em ganhar renda ou em gastá-la, poderiam ser vistas como livres de influências e consequências éticas e altruístas, como se motivados somente por ganhos materiais para satisfazer as necessidades/desejos da natureza mais baixa do homem" (Collini et al., 1983, p. 314).

${ }^{25}$ É nesta possibilidade de medir a força das motivações no campo econômico que Marshall ancora o seu pleito pela autonomia da Economia. Nos Princípios, Marshall mede, do lado da demanda, a força da motivação por consumir um bem pela disposição a pagar (em dinheiro) por este, e do lado da oferta, mede o "sacrifício" associado à produção, pelo o quanto as pessoas exigem (monetariamente) para se submeter a ele (Marshall [1920], 1982, p. 13).
} 
otimista, Marshall acreditava que era nesta direção que a sua sociedade estava caminhando, e que esta trajetória deveria ser estimulada.

Foi apontado que Marshall rejeitou o tratamento estático dado pelos economistas políticos clássicos à natureza humana. E não é exagero afirmar que o melhoramento humano estava no centro da sua filosofia social. ${ }^{26}$ Ademais, o fato de as atividades exercidas pelos homens para "ganhar a vida" serem, segundo ele, ao lado da religião, o principal determinante do caráter humano de cada época (Marshall [1920], 1982, p. 1), tornava o estudo da Economia particularmente importante. Esta ciência além de ser o estudo da riqueza, seria uma parte do estudo do homem (ibidem). Ela seria, assim, instrumental não somente para elevar o nível de vida material, mas também para tornar os homens mais nobres e refinados. ${ }^{27} \mathrm{E}$ era justamente o fato de poder contribuir para este aprimoramento que tornava, para Marshall, a Economia algo que valia a pena ser investigado (Marshall [1920], 1982, p. 3; Reisman, 1987, p. 4).

Podemos encontrar mais do que uma pitada de influência romântica no caráter e nos valores que Marshall gostaria de ver vigorando entre seus contemporâneos. Apesar de obviamente manter-se dentro do marco de uma economia de mercado - influenciado por Carlyle que bradou por uma aristocracia na indústria e por Ruskin que pedia nobreza no trabalho - Marshall demandou uma maior nobreza no agir econômico, o que denominou "cavalheirismo econômico" (economic chilvrary) (Grampp, 1972, p. 357). Este cavalheirismo nos negócios envolveria nobreza, lealdade, altruísmo e o sentimento de que a riqueza seria, não o fim principal, mas quase que um subproduto buscado acima de tudo por ser um indício de sucesso e de distinção (Marshall, 1907, p. 331). ${ }^{28}$ Assim, Marshall almejava uma mudança de valores e, como mencionado, acreditava que a tendência histórica seria esta. Para ele, seria preciso que a opinião pública passasse a diferenciar os bons e os maus homens de negócios e deixasse de valorizá-los apenas na medida

\footnotetext{
${ }^{26} \mathrm{O}$ relato de Marshall sobre um episódio de sua vida revela o que ele considerava a sua missão ao abraçar a economia política: "Por volta da época em que eu resolvi pela primeira vez estudar tão profundamente quanto possível a Economia Política [...] eu vi numa vitrine um pequeno quadro em óleo [de um homem pobre com cara lúgubre e melancólica] e comprei-o por alguns shillings. Eu o coloquei sobre o apoio da chaminé no meu quarto na universidade e, daí em diante, o chamei de meu santo padroeiro e me devotei em tentar achar uma forma de tornar, homens como aquele, pessoas adequadas aos céus. Nesse meio tempo eu fiquei muito interessado na parte semimatemática da Economia Pura, e fiquei com medo de tornar-me um mero pensador. Mas uma olhadela para o meu santo padroeiro parecia trazer-me de volta para o caminho certo [...]"(Marshall, apud Keynes, 1925, p. 38, ênfase adicionada).

${ }^{27}$ Como coloca Viner: “[...] O progresso que ele [Marshall] buscava [...] não era meramente uma questão de mais bens, mas de acesso a, e gosto por, mais lazer, uma vida mais refinada para todas as pessoas, de forma que até os carregadores de varas pudessem ser gentlemens.[...]" (Viner, 1958, p. 250).

${ }^{28}$ Esta concepção é explicitada de forma lapidar no seu ensaio Social Possibilities of Economic Chilva$r y$ (1907). Grampp argumenta que este ensaio foi escrito como uma resposta às criticas feitas aos valores da Economia Clássica que, além de terem influência que não podia ser ignorada, haviam persuadido em alguma medida o próprio Marshall (Grampp, 1972, p. 357).
} 
da riqueza obtida. Esta mudança traria alguns benefícios materiais, mas principalmente benefícios morais:

“[...] caso as gerações vindouras procurassem e honrassem aquilo que é verdadeiramente cavalheiresco nos negócios modernos, o mundo cresceria rapidamente em riqueza material e em riqueza de caráter. Esforços nobres seriam evocados; e mesmo o homem mais estúpido iria gradualmente parar de prestar homenagem à riqueza em si, sem investigar como foi obtida. Ganhar dinheiro por meios sórdidos não teria lugar nessa sociedade [...]" (Marshall, 1907, p. 343).

Fica claro que o "homem ideal" de Marshall estava longe de ser o homem aquisitivo e moralmente degradado de sua época. Seria, ao contrário, um homem com valores nobres, usualmente pouco associados à ordem de mercado, e similares a aqueles exaltados pelos autores românticos. ${ }^{29}$

Marshall também se revelou bastante sensível às críticas lançadas contra a Economia Política no que tange ao tratamento dado à questão da pobreza. Ele assume a posição de que a pobreza não era inevitável e nem tampouco culpa dos pobres, e critica os Economistas Políticos clássicos que "[...] não viam que a pobreza do pobre é a principal causa daquela fraqueza e ineficiência que são as causas da sua pobreza [...]" (Marshall, 1885, p. 155). Ele argumenta, ainda, em consonância com os críticos humanistas, que esses estariam errados por não terem fé na possibilidade de uma melhoria importante e permanente na condição das classes trabalhadoras (ibidem). Por acreditar piamente nesta possibilidade, Marshall tornou o combate à pobreza uma meta a ser continuamente perseguida. Já na maturidade, ao fazer uma avaliação sobre a sua trajetória profissional ele afirma: " $E u$ me devotei nos últimos vinte e cinco anos a problema da pobreza e [...] muito pouco do meu trabalho tem sido devotado a qualquer investigação que não tenha relação com isso" (Marshall, apud Reisman, 1990, p. 10). ${ }^{30}$

Esta sua preocupação com a pobreza relacionava-se diretamente com o seu, já mencionado, desejo de aprimorar os homens. Segundo ele a pobreza, as péssimas condições de habitação, a falta de ar limpo, de parques e de acesso à educação estariam no centro da degradação humana:

\footnotetext{
${ }^{29}$ Shove aponta que o tom mais piedoso e moralista assumido nos Princípios em parte deveu-se ao seu esforço de reabilitar a Economia diante das criticas morais: "Dai vem, entendo eu, (pelo menos parcialmente) uma característica do livro que irrita um pouco o ouvido moderno: a sua reiterada insistência na importância do caráter nos assuntos econômicos e aquelas frases pias e apartes moralizantes que hoje em dia parecem fora de lugar em um tratado científico. [...]”(Shove, 1942, p. 310).

${ }^{30}$ Segundo Keynes, “[...] Marshall era ansioso demais por fazer o bem. Ele tinha uma tendência a subvalorizar aquelas partes intelectuais do assunto que não fossem diretamente relacionadas com o bem estar da humanidade, ou com as condições das classes trabalhadoras ou coisas do gênero [...] e a sentir que quando ele estava investigando estas, ele não estava se ocupando do Elevado (Highest). (Keynes, 1925, p. 36).
} 
"Com melhores casas e melhor comida, com menos trabalho duro e mais lazer, a grande massa da nossa população teria o poder de viver uma vida bem diferente da que leva agora, uma vida bem mais elevada e bem mais nobre." (Marshall, 1885, p. 172, ênfase adicionada).

Assim, por fornecer o conhecimento necessário para diminuir a pobreza e as péssimas condições de vida, a Economia poderia contribuir de forma decisiva para o melhoramento do homem. E fazer com que a Economia de fato cumprisse esse papel foi o compromisso que Marshall abraçou ao assumir a cadeira de Economia Política em Cambridge. Na sua palestra inaugural em 1885 ele descreve a sua missão nesta instituição como sendo:

“[...] aumentar o número daqueles que Cambridge, a grande mãe dos homens fortes, manda para o mundo com cabeças ponderadas, mas corações quentes, dispostos a dar pelo menos parte de seus melhores poderes para combater o sofrimento que os circunda, resolvidos a não ficarem satisfeitos enquanto não tiverem feito tudo em seu alcance para descobrir o quanto é possível abrir, para todos, os meios materiais de uma vida nobre e refinada" (Marshall, 1885, p. 174).

A Economia, nas mãos de Marshall, não podia mais ser acusada de ser indiferente aos problemas das classes trabalhadoras e dos pobres.

\section{CONSIDERAÇÕES FINAIS}

Marshall claramente tinha o objetivo de resgatar o prestígio da Economia e de pôr fim às divergências que assolavam a profissão, e a forma conciliatória com que apresentou as suas concepções certamente ajudou na tarefa de angariar simpatizantes de todas as vertentes envolvidas no debate econômico da época. Por um lado, ele fez concessões às novas ideias sem, no entanto, tripudiar os antecessores, por outro, rejeitou várias das críticas, mas sempre valorizando algum aspecto do pensamento da corrente que as lançou. Esta estratégia foi extremamente bem-sucedida, o dissenso que caracterizara as décadas de 1870 e 1880 desfez-se e um novo consenso se firmou em torno das contribuições de Marshall.

Como aponta Shove, os seus Princípios "[...] adquiriram uma posição se não de dominância tão exclusiva como a que os Princípios de Mill tiveram para a geração pós-1850, pelo menos algo comparável [...]”(Shove, 1942, p. 313). ${ }^{31} \mathrm{O}$ livro

\footnotetext{
${ }^{31}$ Schumpeter ressalta a recepção extremamente positiva que o livro teve e a adequação deste aos humores da época: "Quando finalmente ele [os_Princípios] apareceu em 1890, o sucesso foi completo e instantâneo. O livro foi um grande feito [performance]. E este feito [performance] foi apresentado em uma roupagem atraente que combinava com perfeição com os humores da época e com as preocupações prevalecentes no campo da economia." (Schumpeter, 1941, pp. 237-238). Sobre a nova ortodoxia implantada com a publicação dos Princípios, ver também Dean (1989, p. 134).
} 
virou ortodoxia e "[t]oda uma geração de estudantes - mais de uma, no diz respeito a gerações acadêmicas - foi criada com base nele [brought up upon it]"(ibidem).

No entanto, as qualificações que Marshall fez em relação à crítica teórica e as concessões feitas aos argumentos historicistas e humanistas não devem ser vistas como sendo puramente pragmáticas com a finalidade de apaziguar os ânimos e "costurar" um novo consenso disciplinar. ${ }^{32}$ Marshall estava genuinamente convencido da relevância de várias destas críticas, tanto que incorporou à sua visão diversos elementos considerados importantes pelas correntes analisadas.

Quando consideradas apenas questões referentes à teoria do valor e distribuição, as semelhanças entre as suas concepções e as da corrente de crítica teórica saltam aos olhos. Marshall foi um marginalista e, de fato, consolidou o marginalismo na Inglaterra - e geralmente é este aspecto de sua obra que é ressaltado. No entanto, ele foi um marginalista sui generis. Por um lado, apresentou, sob influência das correntes adeptas do método histórico, uma visão dinâmica de sociedade e de natureza humana que enfatizava a evolução histórica e assumiu uma postura metodológica que valorizava igualmente a teoria e a observação dos fatos. Por outro, o contato com as concepções das correntes humanistas, deixou a sua marca no tom moral e piedoso dos seus escritos.

Inegavelmente, o maior legado de Marshall para a Economia moderna foi justamente a parte de teoria do valor e da distribuição. Os seus seguidores trataram de expurgar as metáforas biológicas, enfatizando a parte estática dos Princípios, e de eliminar o tom moralizante e, em certa medida, piegas presente na sua obra. No entanto, se o rótulo de "pai da microeconomia" atribuído ao Marshall é aceito sem reservas, e se as outras dimensões de suas contribuições são ignoradas, chega-se a uma visão distorcida e empobrecida das concepções e dos objetivos deste grande autor do pensamento inglês.

\section{REFERÊNCIAS BIBLIOGRÁFICAS}

ARGYROUS, G. [1990] (1996) “The growth of knowledge and economic science: Marshall's interpretation of the classical economists”. In Alfred Marshall: Critical Assessments Second Series, Routledge, New York:.47-55.

\footnotetext{
${ }^{32}$ Apesar de Reisman [1990] enfatizar este lado conciliador e pragmático de Marshall, ele aponta que este autor rechaçava insinuações desta natureza. Ele rejeita a ideia de que tenta "[...]" acomodar" ou "reconciliar" escolas divergentes do pensamento. Tal empreendimento me parece tolice (trumpery). A verdade é a única coisa que vale a pena ter: não paz. Eu nunca transigi em relação a qualquer doutrina de qualquer tipo" (Marshall, apud, Reisman, 1990, p. 91). No entanto, Collini et al. ao citarem essa mesma passagem acrescentam que ela continua da seguinte forma: "[...] escolher a terminologia que poderia expressar a verdade era uma "questão de mero oportunismo" no qual era necessário conceder sempre que parecesse provável que isto 'facilitasse o entendimento mútuo"” (Collini et al.,1983b, p. 313). E o ato de colocar as coisas de forma que "facilitasse o entendimento" Marshall praticou com alguma frequência. É aí que entra o seu espírito conciliatório.
} 
BLADEN, V.W. (1941) "Mill to Marshall: The conversion of the economists”. In The Journal of Economic History, Vol.1, Supplement: The Tasks of Economic History: 17-29.

COATS, A.W. (1954) "The historicist reaction in English political economy 1870-90", Economica, vol.XXI (82): 143-153.

(1968) "The origins and early development of the royal economic society", The Economic Journal, 78 (310): 349-371.

COLLINI, S. et al.. (1983) That Noble Science of Politics: A Study in nineteenth-century intellectual history. Cambridge, Cambridge University Press.

DEAN P. (1989) The State and the Economic System: an Introduction to the History of political Economy Oxford: Oxford University Press.

FOXWELL, H.S. (1887) “The economic movement in England”, The Quaterly Journal of Economics, 2 (1): 84-103.

GRAMPP, W.D. (1972) “Classical economics and moral critics”, History of Political, 5 (2).

GROENEWEGEN, P.D. [1988] (1996) “Alfred Marshall and the establishment of the Cambridge economic tripos”. In Alfred Marshall Critical Assessments Second Series vol. II, ed. John Cunningham Wood, New York: Routledge.

HODGSON, G.M. (1993) “ The Mecca of Alfred Marshall”, The Economic Journal, 103 (417): 406415.

HUTCHISON, T.W. (1972) “The 'Marginal Revolution' and the decline and fall of English classical political economy”, HOPE, 4 (2): 443-468.

JEVONS, W.S. [1871] (1996) A Teoria da Economia Politica. Coleção Os Economistas, Nova Cultural, São Paulo.

KEYNES, J.M. (1936) “Herbert Somerton Foxwell”. In The Economic Journal, vol. 46, n.184, p. 589611.

[1925](1966) “Alfred Marshall, 1842 - 1924”. In: Memorials of Alfred Marshall. Ed. A.C. Pigou, New York, Augustus M. Kelley.

MATTOS, L.V. (1999) "A Economia Política como uma ciência autônoma: Um estudo sobre as contribuições metodológicas de John Stuart Mill.” Revista de Economia Política, n. 4 (76).

MARSHALL, A. [1885] (1966) "The present position of Economics". In Memorials of Alfred Marshall. Ed. A.G.Pigou. A.M.Kelley, New York.

[1907] (1933) “Alfred Marhsall, the Mathematician as seen by himself”.In Econometrica, vol.1 n.2, pp.221-222.

[1907], (1966) “ The Social Possibilities of Economic Chilvary" in Memorials of Alfred Marshall. Ed. A.C. Pigou, Augustus M. Kelley, New York.

[1920](1982) Principles of Economics. Porcupine Press, Pennsylvania.

MILL, J.S. [1836] (1967). "On the definition of Political Economy and the Method of philosophical investigation in that science". In CW IV, University of Toronto Press, Toronto.

[1843] (1987) The Logic of moral science, a repress of A System of Logic, Book VI, Ducksworth, Londres.

O'BRIEN, D.P. (1997) "Marshall and his Correspondence". In The Economic Journal vol. 107, n. 445, p. $1859-1885$.

PERSKY, J. (1990) “Retrospectives: A Dismal Romantic”. In Journal of Economic Perspectives, vol.4 n.4, p. $165-172$.

(1995) “Retrospectives: The Ethology of Homo Economicus". In Journal of Economic Perspectives, vol. 9, n.2, p. 221-231

REISMAN, D. (1987) Alfred Marshall: Progress and Politics. Macmillian Press, London. (1990) Alfred Marshall's Mission. Macmillian Press, London.

ROBBINS, L. (1982) "The Place of Jevons in the History of Economic Thought". In The Manchester School, n.4.

SCHABAS, M. “Alfred Marshall, W. Stanley Jevons, and the Mathematization of Economics”. In Isis, vol. 80, n.1, 1989, pg. 60-73. 
SCHUMPETER, J. A. [1954] (1966) History of Economic Analysis. Oxford Univerty Press, New York.

(1941) “Alfred Marshall's Principles: A Semi-Centennial Appraisal”, The American Economic Review, 31 (2): 236-248.

SCREPANTI, E. et al. (1995) An outline of the History of Economic Thought. Oxford: Claredon Press.

SHOVE, G.F. (1942) "The Place of Marshall's Principles in the Development of Economic Theory". The Economic Journal, 52 (208): 294-329.

VINER, J. (1958) “Marshall's Economics in Relation to the Man and to His Times". In The Long View and the Short, Illinois.

WINCH, D. (1985) “Introduction”. In John Stuart Mill, Principles of Political Economy: Books IV and V. New York: Penguin Classics, Penguin Books. 